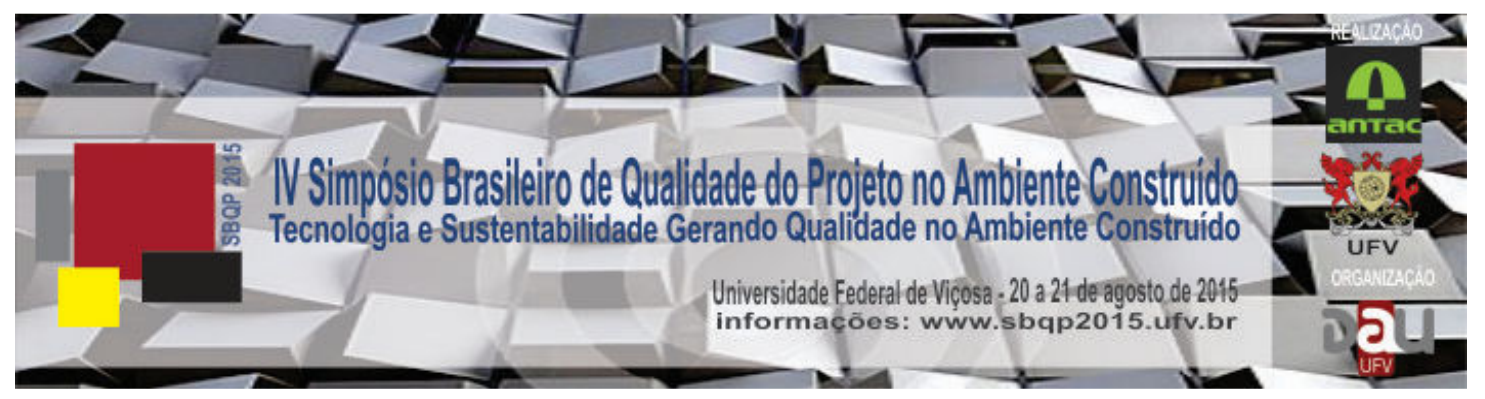

\title{
NOVAS TENDÊNCIAS EM EDIFÍCIOS VERTICAIS NA ORLA DE MACEIÓ - O EDIFÍCIO NAVEGANTES 1
}

\author{
CAVALCANTE, Morgana \\ Universidade Federal de Alagoas, morganaduarte@ig.com.br
}

\begin{abstract}
RESUMO
O presente artigo visa demonstrar, através de estudo de caso, as estratégias projetuais contemporâneas em edifico vertical na orla de Maceió-Alagoas, fruto de pesquisa de tese de doutoramento do PPGAU-FAU-Mackenzie entre os anos de 2010-2014, a partir do exemplo da análise do edifício Navegantes. A metodologia adotada foi a da leitura visual do projeto inserido no contexto da cidade. Como resultado observou-se uma significativa mudança do modo de morar em edifícios verticais a partir de novas tipologias ditadas pelo mercado e pela própria configuração dos lotes remanescentes na orla da cidade.
\end{abstract}

Palavras-chave: Estratégias, Projeto, Edifício vertical

\begin{abstract}
This article aims to demonstrate, through case study, contemporary projective strategies in vertical buildings on the edge of Maceió-Alagoas, from a PHD research at PPGAU-FAU-Mackenzie between the years 2010-2014, with an example of the analysis of Navegantes building. The methodology included is the visual reading of the inserted project in the context of the city. As a result, there was a significant change in the live mode in vertical buildings from new types dictated by the market and by the configuration of the remaining lots on the edge of the city.
\end{abstract}

Keywords: Strategies, design, vertical Building

\section{INTRODUÇÃO}

A cidade de Maceió, no nordeste do Brasil tem nos últimos anos observado novas tipologias de edifícios verticais, especialmente no que concerne às suas implantações em lotes longilíneos, o que de certa forma permitiu uma maior liberação para espaços de lazer em seus pilotis. Esta é uma das novas tendências atreladas aos lotes remanescentes de frente para praia de Jatiúca, na orla norte da cidade e também às novas exigências do mercado, na qual o condomínio passa a atender aos anseios de morar em espaços com

\footnotetext{
1 Trabalho apresentado no IV SBQP 2015. Universidade Federal de Viçosa. Disponível em: doi> http://dx.doi.org/10.18540/2176-4549.6054
} 
infraestrutura mais completa de lazer tais como, espaços gourmet, espaços fitness e churrasqueiras.

A partir de pesquisa desenvolvida em Doutorado em Arquitetura e Urbanismo no PPGAU da FAU-Mackenzie-SP, entre os anos de 2010-2014, foram analisados 12 edifícios verticais na área de estudo, orla marítima norte de Maceió-AL. Como exemplo a ser analisado neste artigo destaca-se o condomínio Navegantes (2003), na avenida Álvaro Otacílio, Jatiúca, projeto do arquiteto Mário Aloísio Melo, que na realidade comporta 02 torres inseridas no lote, com área de lazer entre os dois edifícios e faz parte do grupo de edifícios, que no final dos anos 90 e início dos anos 2000, se instalaram na orla da Jatiúca (fig.01). Desta forma, a pesquisa tem o objetivo de verificar suas estratégias projetuais contemporâneas, buscando identificar elementos que caracterizem a hipótese desta tendência da contemporaneidade.

\section{Figura 1- Orla de Jatiúca}

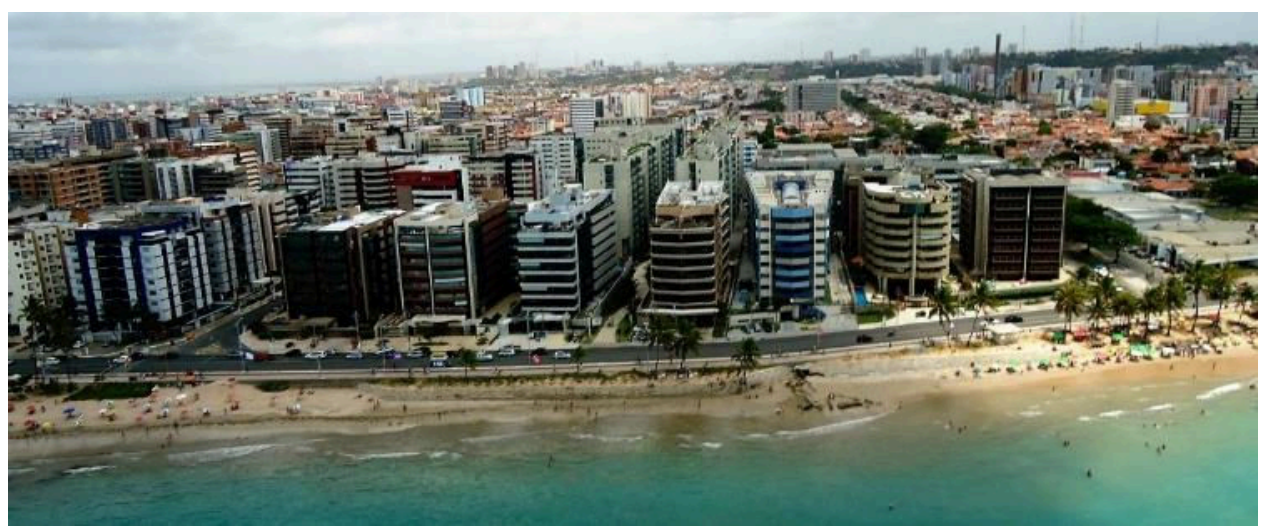

Fonte: Toni Cavalcante, 2012

\section{FUNDAMENTAÇÃO E MÉTODO DE ANÁLISE}

Para a construção do método de análise desta pesquisa foram investigados conceitos apreendidos de autores como Comas (1986), Villac (2002), Zein (2005), Ching(1998), e Ferrara (2000), com seus respectivos processos de análise e interpretação.

Comas (1985), em seu livro "Projeto Arquitetônico Disciplina em Crise, Disciplina em Renovação", utiliza-se de três parâmetros básicos a partir das especificações formais do projeto: as especificações de natureza técnicoconstrutiva; as especificações de natureza figurativa, enfatizando a análise da composição; e as especificações formais, que se exprimem em analisar a configuração, associação e distribuição de volumes.

Em Ferrara a discussão perpassa por analisar o edifício a partir de sua inserção no urbano sob a ótica da visibilidade e a partir de Villac e Zein a interpretação a análise vai além da descrição do edifício para fazer a sua correlação com a crítica em seu devido tempo e lugar. Assim, os critérios de análise se baseiam na leitura do projeto dentro do cenário da cidade. São considerados critérios disciplinares (tipologia de lote, implantação, especificações espaciais e formais, partido tecnológico e linguagem do edifício) e interpretativos. 
Desta forma, a análise foi feita a partir do estudo de caso na orla norte da cidade de Maceió, selecionando-se o edifício Navegantes como exemplar a ser analisado neste artigo a fim de se verificar as suas estratégias projetuais.

\section{ESTUDO DE CASO: O CONDOMÍNIO NAVEGANTES EM MACEIÓ}

O Navegantes é um desses edifícios, cujas particularidades vão além da implantação em lote estreito, reunindo a síntese da evolução formal do arquiteto Mário Aloísio Melo desde os anos 80 até o início dos anos 2000. Nele, - vidro aparece com parcimônia, entretanto as estratégias utilizadas pelo arquiteto permitem ampla visão da orla e transparência pela disposição da própria forma, que inicialmente se insinua para o espectador, como arredondada, entretanto, o projeto utiliza-se desse recurso para aproveitar as vistas, já que o corpo do primeiro bloco do edifício desenvolve-se linearmente ao longo do terreno. A fachada arredondada integra-se à orla curva, o que confere leveza à forma.

\subsection{Implantação e Tipologia de lote}

Com relação à implantação e tipologia de lote, o residencial Navegantes insere-se em um lote de face de quadra, expande-se linearmente ao longo de um terreno trapezoidal de $2489,96 \mathrm{~m} 2$, ocupando uma área total construída de $9631,40 \mathrm{~m} 2$ e taxa de ocupação de $50 \%$ (1.244,98m2). A implantação de dois volumes que se conectam através da área de lazer comum constitui uma das estratégias projetuais utilizadas pelo arquiteto para obter maior aproveitamento da taxa de ocupação do lote e as compensações permitidas pelo código vigente. De certa forma, a disposição dos volumes no lote foi resultado da legislação em vigor e das restrições de altura do cone do farol da Marinha (à época), que desenham os dois edifícios formalmente e funcionalmente. (figs.02 e 03)

Figura 2- Implantação

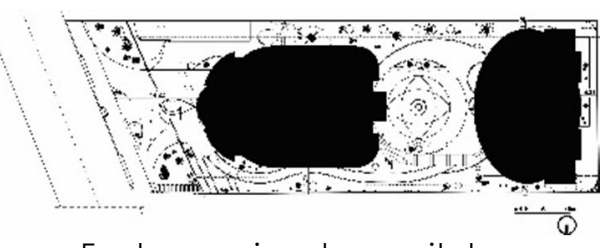

Fonte: arquivo do arquiteto

Figura 3 - Planta de locação e coberta-conjunto

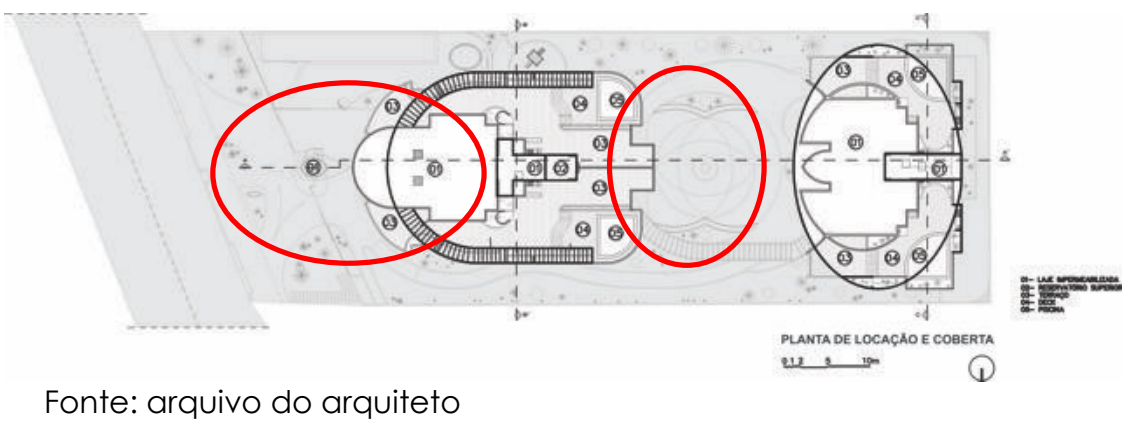


A estratégia permite a distribuição de dois blocos pontuais, porém que se conectam linearmente pela área de lazer interna, o que evidencia a implantação em lote cuja dimensão menor está voltada para a orla e a maior estende-se linearmente, mais uma vez evidenciando que o desenho do lote contribui para a locação e desenho do conjunto de blocos. Os dois blocos não chegam a ser totalmente distintos, pois dialogam através de suas formas e elementos de textura e cor. (fig.04)

Percebe-se dessa forma que a implantação também tem o nítido interesse em valorizar a ideia das vistas para o mar. O acesso se dá pela rua Álvaro Otacílio, inicialmente por uma guarita que não chega a se destacar em relação ao conjunto, inclusive se harmonizando pelo próprio formato em curva que apresenta.

Os pilotis de cada um dos blocos se conectam através da ampla área de lazer que permite uma certa fluidez visual em um percurso comum pelo espaço destinado ao lazer. Na área de lazer comum, distribuem-se a piscina no formato retangular (raia) paralelamente a uma das laterais do terreno, a piscina infantil, o deck, o lavabo, a churrasqueira e o playground. (fig.03)

O agenciamento é trabalhado através de formas orgânicas, aproveitando os movimentos das curvas sinuosas do jardim e seus recantos, inclusive com a implantação de um caramanchão que liga os dois edifícios. (fig.03)

O subsolo ocupa praticamente todo o terreno em uma disposição linear composta pelas vagas dos carros, elevadores de serviço e social e depósito e casa de máquinas.

\subsection{O Edifício Navegantes 1}

\subsubsection{Especificações espaciais e formais}

Em relação às especificações espaciais e formais do Ed. Navegantes 1, destacam-se as seguintes observações:

O edifício vertical multifamiliar possui subsolo, pilotis, mezanino, 5 pavimentos tipo, sexto pavimento e cobertura.

\subsubsection{Setorização e compartimentação}

Figura 4: Navegantes 1

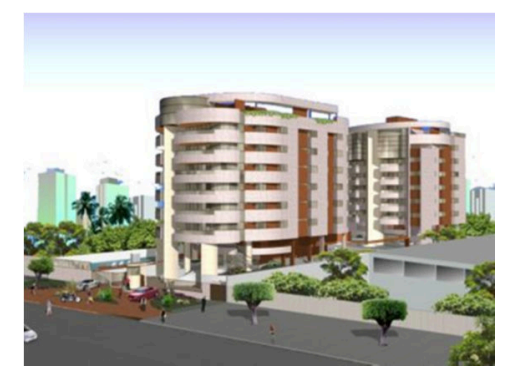

Fonte: arquivo do arquiteto(2003) 


\section{Figura 5 - Planta - Baixa- Pav. Tipo - Navegantes 1}

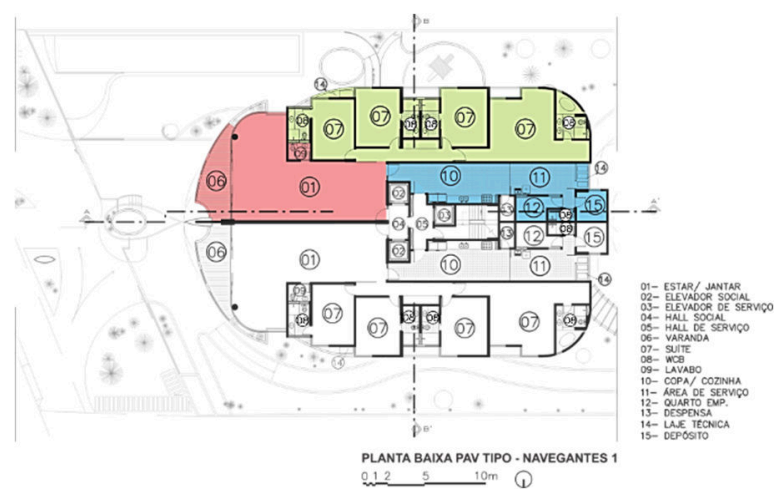

Fonte: arquivo do arquiteto

\section{Figura 6 - Planta-Baixa - 6 pavimento - Navegantes 1}

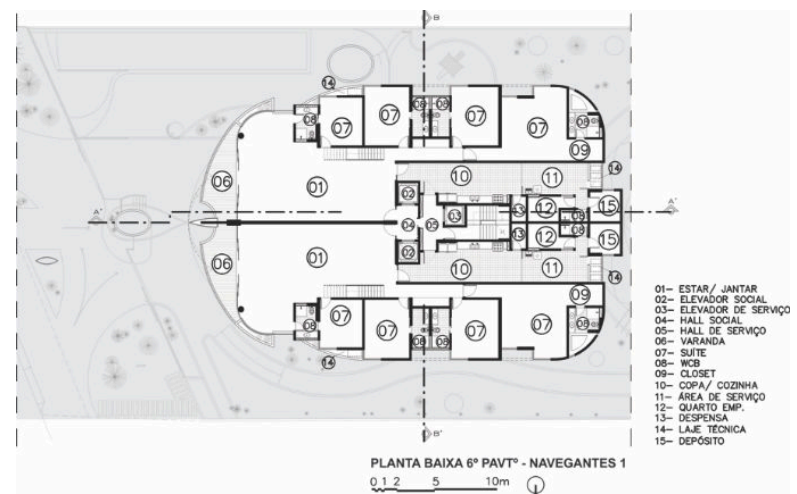

Fonte: arquivo do arquiteto

O pilotis do Navegantes 1 apresenta grande fluidez através de suas áreas abertas (terraços e jogos) pelas quais há conexão com o exterior, sendo o primeiro contato com o exterior através da marcação de suas colunas em espaço aberto e fluido, para, posteriormente direcionar o transeunte ao hall social envidraçado. No pilotis, encontram-se, além do hall social, as circulações verticais, o depósito e, na parte posterior, a sala para motoristas.

O mezanino apresenta acesso através dos elevadores (sociais e de serviço) e de escada circular, marcando bem e estrategicamente o seu salão de festas em formato de semicírculo. O ambiente atrai o olhar de quem penetra ainda no pilotis do Navegantes 1 , em virtude da escada escultórica direcionada ao mesmo. Ainda no mesmo encontram-se os espaços destinados ao bar de apoio ao salão de festas e espaços de atividades físicas (ginástica, musculação), sauna, relax, massagens e os wcs.

O pavimento tipo (5 pavimentos) distribui-se linearmente ao longo do eixo do terreno de topografia plana, com dois apartamentos por andar, sendo cada um com aproximadamente $272,0 \mathrm{~m} 2$ de área. Cada apartamento possui 
estar/jantar, quatro suítes c/ wcb, varanda, lavabo, copa/cozinha, área de serviço, despensa, depósito e quarto de empregada. (fig.05).

A fluidez do partido permite transparência por suas varandas frontais e através do jogo de escalonamento das suítes, com o recuo dos banheiros para possibilitar maior aproveitamento das vistas.

A estratégia evidenciada no partido é a setorização racional dos ambientes, mais uma vez valorizando os espaços servidos em relação aos servidores.

A área social tem valorizada a vista para o mar, bem como a íntima, cujo jogo de recuos dos banheiros também possibilita melhor visão. A área de serviço é bem marcada e direcionada para a parte posterior da edificação. (fig.05)

Verifica-se certa unidade dentro do conjunto pelo uso que se repete dos ambientes em formato quadrangular ou retangular, excetuando-se as varandas com bordas arredondadas.

O sexto pavimento, com dois apartamentos, é praticamente igual ao pavimento tipo, sendo que cada um incorpora uma escada que se direciona à cobertura, diminuindo a área de uma das suítes para inserção da escada e eliminando o lavabo. (fig.06)

A cobertura apresenta estar/jantar, suíte com wcb, home theater, terraço livre, deck, piscina, área para chuveirão, churrasqueira, wc e casa de máquinas. A área livre do terraço permite que a ideia de área de lazer na cobertura seja explorada. Observa-se que a ocupação na cobertura se deu em núcleo central que se distribui simetricamente, liberando os vazios das laterais da edificação, o que permite maior fluidez visual.

\subsubsection{O Conforto}

O partido apresenta atividades distribuídas setorialmente e hierarquicamente, privilegiando, no setor social e quartos, a vista e a recepção dos ventos NE e SE. Na área de maior insolação, voltada para o oeste, o arquiteto implantou a área de serviço, o depósito e os banheiros, entretanto, introduziu laje técnica conferindo certa proteção à insolação direta. (fig.07)

\section{Figura 7 - Ventilação - Navegantes 1}

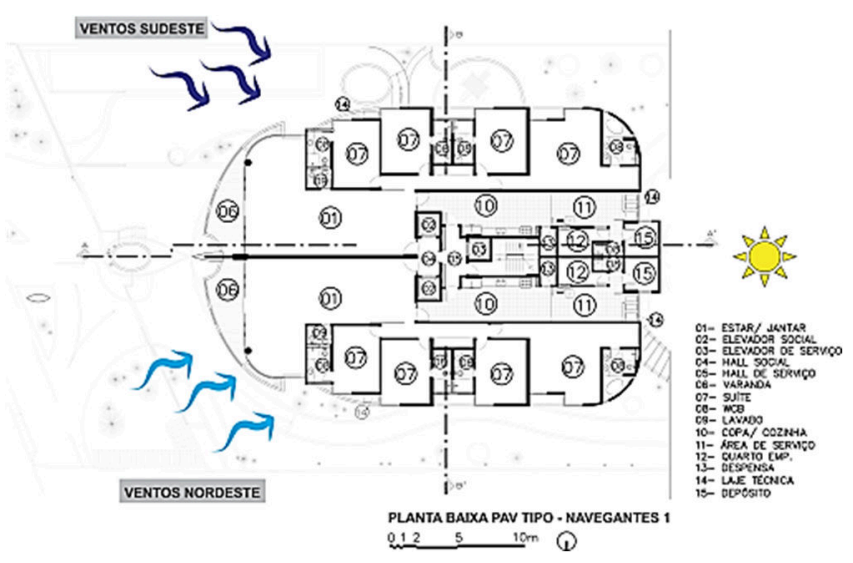

Fonte: Arquivo do Arquiteto (modificado pelo autor) 


\subsubsection{Fachadas}

No edifício Navegantes 1, a fachada principal encontra-se dividida simetricamente, em equilíbrio bilateral. Cada apartamento encontra-se em um desses lados da fachada, onde ocorre o equilíbrio entre os cheios e vazios. A fachada principal, voltada para o leste, pode ser dividida em três partes: a marcação de entrada de onde se destacam os pilares do pilotis, as varandas dos pavimentos tipo e os volumes em vidro que arrematam o edifício a partir de sua cobertura. A horizontalidade das faixas que marcam a fachada do edifício não acentua a pouca altura do artefato, pois o septo, que divide os apartamentos simetricamente, evidencia a sua verticalidade.

As fachadas laterais apresentam-se equilibradas visualmente, com variação de revestimentos (vidro, pastilha e granito) e com arremate na cobertura, em forma de curva, unificando-as em relação à fachada frontal.

Já a fachada de fundos, apresenta predominância dos cheios em relação aos vazios conferido maior proteção quanto à insolação direta, através de recuo da área de serviço e implantação de laje técnica.

\section{Figuras. 08 e 09 - Estudos Volumétricos - Navegantes 1}
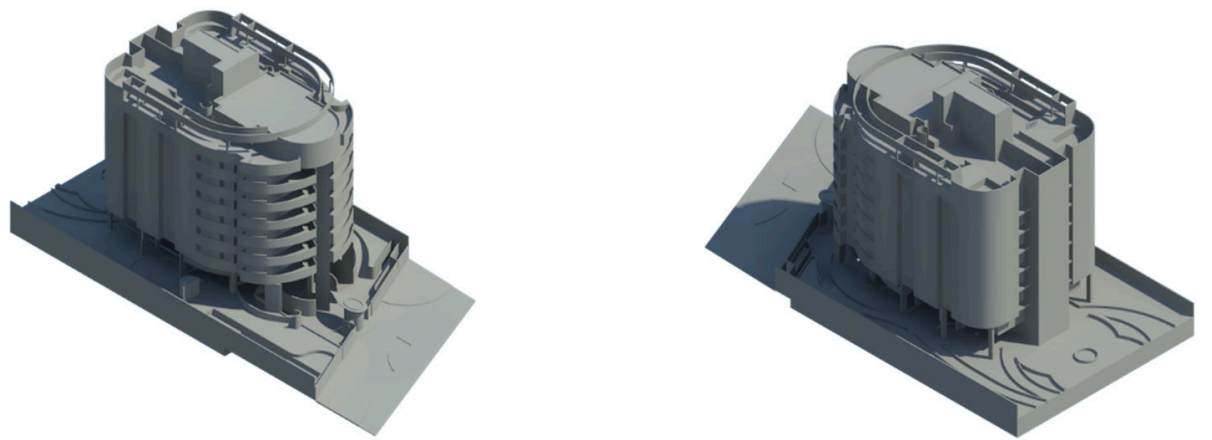

Fonte: Arquivo do Autor

\subsubsection{O Volume}

O volume permite a sensação circular do edifício, pela correção e arremate feitos na fachada, através da jardineira e abaulamento dos vértices, permitindo a ideia de curvatura. Há um septo (fachada frontal) acentuando a verticalidade da edificação e que serve também de separação entre as varandas dos apartamentos. Interessante também destacar o arremate da cobertura, em curva, através da correção. (figs. 08 e 09)

As varandas, de uma maneira geral, possibilitam o "estar dentro" da edificação e "ao mesmo tempo fora", em contato com a natureza, em uma relação dialética entre o interior e o exterior, além de a curva proporcionar o acompanhamento da topografia da orla em um diálogo sincrônico entre interior e exterior.

As colunas circulares e de pé-direito duplo também acentuam a ideia do edifício em fluidez com o espaço externo, a partir de seu pilotis, em uma estratégia que, junto com o septo frontal, faz a marcação de entrada.

Os recortes no bloco e a inserção do material vidro na fachada constituem notadamente uma estratégia que permite maior movimento e quebra a 
rigidez do bloco, proporcionando tridimensionalidade dinâmica, mas em equilíbrio visual. (figs. 08 e 09)

\subsubsection{Partido tecnológico}

O partido tecnológico, através de sua materialidade, com o uso do granito, de pastilhas e revestimento em alumínio (painel de alumínio composto) usado nas pilastras, confere textura lisa na fachada frontal, e, ao lado do uso do vidro bronze, promove uma leitura equilibrada e atual do edifício. As varandas em balanço, as janelas envidraçadas marcando as horizontais do edifício e o volume em pele de vidro sacando a partir da cobertura, com independência da fachada em relação ao sistema estrutural, revelam uma estratégia ainda moderna. A estrutura utiliza o sistema de laje alveolar ${ }^{2}$, facilitando a flexibilização dos espaços, especialmente as vagas de automóveis no subsolo.

\subsection{7 linguagem}

A linguagem do edifício incorpora estratégias como a setorização, a fluidez em sua implantação e em sua materialidade (vidro), a estrutura e a independência entre as partes, o aproveitamento da cobertura com amplas áreas de lazer e o pilotis. Mostra uma relação com as raízes do Moderno, no que se refere à organização espacial, entretanto, a sua volumetria incorpora uma leitura mais contemporânea com relação ao tratamento e à materialidade.

\subsection{O Edifício Navegantes 2}

\section{Figura10- Navegantes 2}

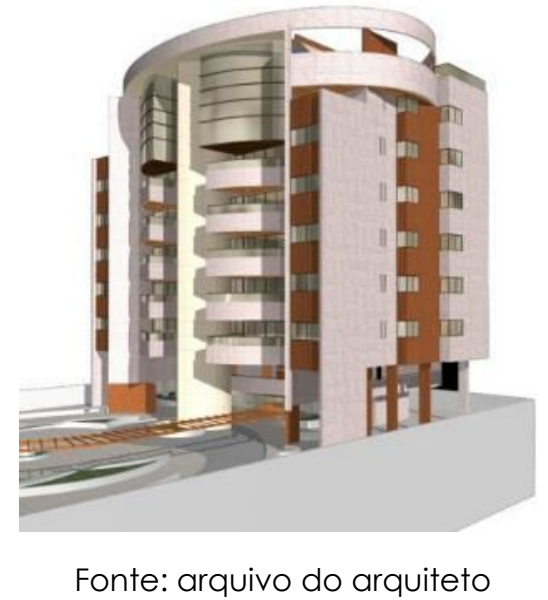

${ }^{2}$ Conforme informação do engenheiro Hélio Abreu, um dos sócios da construtora Record. 

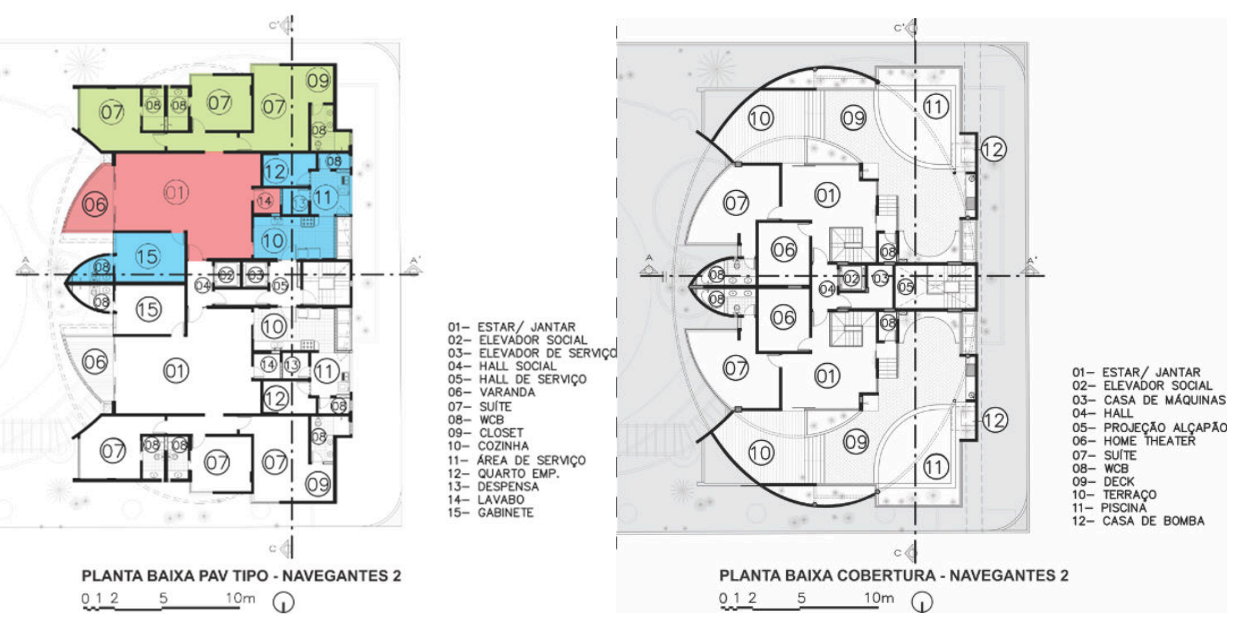

Fonte:Arquivo do Arquiteto (modificado pelo autor)

\subsubsection{A implantação}

A implantação do Navegantes 2 fica na parte posterior do lote, entretanto a vista é para a área de lazer. (fig. 02)

\subsubsection{Especificações espaciais e formais}

Setorização e Compartimentação

O pavimento tipo (5 pavimentos) distribui-se em dois apartamentos tipo, cada um com aproximadamente 187,00 m2, com estar/jantar, varanda, três suítes, gabinete, lavabo, cozinha, área de serviço, despensa e wcb. O pavimento tipo distribui-se através de setores bem definidos, valorizando-se as vistas do setor social e do íntimo. Nesse pavimento a circulação vertical localiza-se no eixo que divide os dois apartamentos de cada pavimento. Há uma clara simetria bilateral que permite uma distribuição sem hierarquias no pavimento tipo. O sexto pavimento se expande conforme o tipo, acrescentando-se as escadas que conectam o andar à cobertura. (fig. 11 e 12)

As varandas se destacam pelo formato arredondado e se separam visualmente de cada um dos apartamentos pelos wcbs dos gabinetes, além de se repetirem em marcação horizontal ao longo dos cinco pavimentos-tipo, em complementaridade de formas que visualmente buscam se encaixar em um semicírculo.

Figura 13 - Ventilação - Navegantes 2

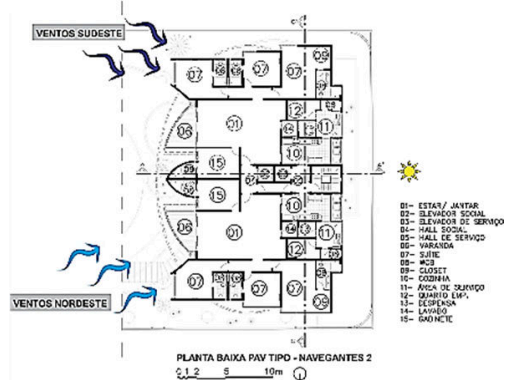

Fonte: Arquivo do Arquiteto (modificado pelo autor) 


\subsubsection{Conforto}

Quanto ao conforto, tem-se a predominância dos ventos SE e NE, privilegiando as áreas sociais e íntimas, e com insolação na parte posterior da fachada (serviço) (fig. 13)

Na cobertura, a ampla visão destacada da suíte reforça a ideia de transparência visual ao deixar a paisagem do ambiente se conectar com o interior. O pavimento apresenta área com estar/jantar, hall, elevador, home theater, suíte, wcb, terraço, deck com piscina. (fig. 13)

\subsubsection{Fachadas}

A fachada frontal do Navegantes 2 é simétrica, dividida em duas partes a partir de um septo vertical. Já horizontalmente, pode ser dividida em três partes: a primeira, corresponde ao acesso ao edifício; a segunda, corresponde aos pavimentos-tipo com as varandas em curvas e a terceira parte, corresponde a elemento em vidro bronze que saca do sexto pavimento e da cobertura. Tal estratégia permitiu ao arquiteto dinamizar a fachada por sua geometria e materialidade (vidro, alumínio, pastilhas e granito), conferindo harmonia com o conjunto dos edifícios e demarcando a individualidade do Navegantes 2.

Já nas fachadas laterais os cheios são demarcados pelas faixas verticais em granito e os vazios se destacam pelas janelas escalonadas para aproveitamento das vistas. $O$ desenho da fachada favorece à verticalidade do edifício. Já na fachada de fundos, prevalecem os cheios em relação aos vazios das esquadrias do serviço, recuadas por lajes técnicas.

\subsubsection{O volume}

O volume se destaca por seu coroamento, com formas circulares que se destacam enquanto elementos que dialogam com o todo do condomínio (Navegantes 1 e 2). As varandas que sacam se inserem em um semicírculo imaginário que confere a percepção da forma circular. $O$ volume também é simetricamente dividido por um septo, sendo que, na cobertura, o detalhe em pano de vidro confere leveza ao edifício. De uma forma geral, o volume se apresenta em diálogo com o todo edificado. (fig.14 e 15)

\section{Figuras 14 e 15 - Estudo Volumétrico- Navegantes 2}
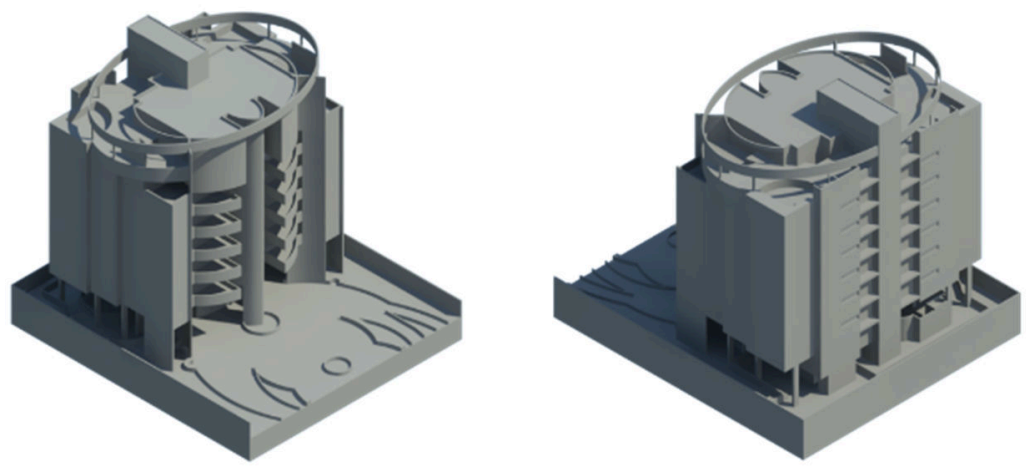

Fonte: Arquivo do Autor 


\subsubsection{O partido tecnológico}

A estrutura organiza-se através do sistema das lajes alveolares, liberando espaços para melhor aproveitamento dos estacionamentos. De uma maneira geral, segue o esquema do Navegantes 1, com revestimento em granito, alumínio, pastilhas e vidro.

\subsection{7 linguagem}

A linguagem entra em harmonia como no Navegantes 1, no sentido de não haver desvinculação visual entre os edifícios do lote e o conjunto edificado na orla da Jatiúca, através dos exemplares que surgem durante o início do século XXI, com o comprometimento no tocante à linguagem contemporânea, mas recorrendo ao moderno em suas estratégias projetuais, especialmente nas plantas-baixas.

\section{CONSIDERAÇÕES FINAIS}

Ao se analisar o Residencial Navegantes dentro do contexto no qual o mesmo está inserido percebe-se que o edifício (conjunto edificado) dialoga com a cidade, especialmente porque seu partido exprime, não só através de sua materialidade, uma ideia de contemporâneo. $O$ uso do material vidro aparece não apenas com o intuito de dialogar com o contemporâneo, mas também permitir uma relação com o entorno, ao capturar para dentro de si a paisagem que o circunda. Nota-se que há certa preocupação de direcioná-lo especificamente nas fachadas onde não há maior incidência dos raios solares. A partir da reflexão que a visibilidade permite, o conjunto edificado apresentase como um "produto" materializado do ideal contemporâneo de morar na orla. Entretanto, importa ressaltar que o edifício se encontra em área da orla que reúne outros edifícios estudados nesta tese, cujo conjunto edificado (prédios de alto padrão), por si só, significa mudança para a área da orla da Jatiúca, especialmente durante os anos 2000.

Desta forma, pontuam-se algumas questões em relação ao conjunto edificado da orla nos 2000.

1. O residencial Navegantes destaca-se enquanto projeto cujas estratégias projetuais se amoldaram aos lotes remanescentes longitudinais da orla da Jatiúca, ao código vigente e à incorporação de espaços mais generosos de lazer entre dois edifícios; fato também observado em outros conjuntos edificados da época e que se diferenciaram por este tipo de configuração espacial, tais como o residencial Portucale.

2. O lote longitudinal permite a implantação de 2 torres com espaço de lazer entre as duas, destacando-se como nova tipologia, o que anteriormente não parecia em projetos da orla.

3. A utilização, em sua materialidade, de texturas com elementos recorrentes como o vidro, o granito e cerâmica; sendo que especialmente nos anos 2000 o vidro vai ser mais explorado.

4. Perpetuação do uso de varanda buscando aproveitamento da vista par ao mar e como elemento de proteção, mesmo que posteriormente esta seja fechada. 
5. Perpetuação das estratégias projetuais modernas que privilegiam a tripartição dos ambientes (social, íntima e serviço)

6. A curva nas edificações aparece como correção da fachada, como estratégia de se interagir com a curvatura da orla, uma vez que os arquitetos passam a ter mais restrições construtivas em relação ao uso de curvas pelo mercado.

\section{REFERÊNCIAS}

CHING, F. D. K. Arquitetura. Forma, espaço e ordem. São Paulo: Martins fontes, 1998.

COMAS, C. E. (org.). Projeto arquitetônico, disciplina em crise, disciplina em renovação. São Paulo: Projeto, 1986.

FERRARA, L. D'A. Design em espaços. São Paulo: Edições Rosari, 2002.

VILLAC, M. I. La construcción de la mirada - Naturaleza, Discurso y Ciudad en la Arquitectura de Paulo Archias Mendes da Rocha. 2002. tese (Doutorado em Arquitetura) - ETSAB/UPC, Escuela Técnica Superior de Arquitectura de Barcelona, Barcelona. 